\title{
BIOPELÍCULAS PRODUCIDAS CON CÁSCARA DE NARANJA Y REFORZADAS CON CELULOSA BACTERIANA
}

\author{
Evelin Alata Mayhuirec ${ }^{\mathrm{c}}$ Yuri Cuadros Huamaníc, Luis Miranda Zanardib, \\ Esperanza Medina de Miranda*a
}

\begin{abstract}
RESUMEN
En este estudio se han elaborado biopelículas a partir de cáscara de naranja, utilizando pectina, en calidad de reticulante y glicerina que hace las veces de plastificante. Asimismo, se ha determinado el efecto de la adición de celulosa bacteriana, obtenida de la fermentación estática de kombucha (Manchurian fungus), en tales biopelículas. Es destacable que la cáscara de naranja ha sido sometida previamente a un proceso de extracción por arrastre de vapor para recuperar su aceite esencial.

Experimentalmente, se encontró que una formulación adecuada de biopelículas contiene los porcentajes másicos siguientes: cáscara de naranja, 15; celulosa bacteriana, 5; pectina, 40; y glicerina, 40. Dicha biopelícula ostentó una resistencia a la tensión de 5,53 N/mm², elongación de 51,60 \% y permeabilidad de 0,0273 g.mm/(h.kPa.m²).

El contenido de pectina afectó significativamente las propiedades de las biopelículas, debido a su interacción con el glicerol. La celulosa bacteriana contribuyó a incrementar la resistencia a la tensión de las biopelículas, pero redujo su elongación, y permeabilidad, Por ello se constituye en un agente reforzante efectivo cuya producción es sencilla y segura.
\end{abstract}

Palabras clave: biopelículas, cáscara de naranja, celulosa bacteriana, propiedades mecánicas y de barrera.

\section{BIODEGRADABLE FILMS PRODUCED WITH ORANGE PEEL AND REINFORCED BY BACTERIAL CELLULOSE}

\footnotetext{
ABSTRACT

This work proposes the formulation of biofilms out of orange peel, using pectin as a crosslinking agent and glycerol as plasticizer. Also, it was determined the impact of the addition of bacterial cellulose obtained from the static fermentation of kombucha (Manchurian

a Facultad de Ingeniería de procesos, Departamento Académico de Ingeniería Química, Universidad Nacional de San Agustín de Arequipa, Av. Independencia 552, Arequipa, Perú, emedinale@unsa.edu.pe

b Facultad de Ingeniería de procesos, Departamento Académico de Ingeniería Química, Universidad Nacional de San Agustín de Arequipa

c Facultad de Ingeniería de procesos, Escuela profesional de Ingeniería Química, Universidad Nacional San Agustín de Arequipa
} 
fungus) in such biofilms. It is noticeable that the orange peel has been subject previously to an extraction process by steam distillation to recover its essential oil.

Experimentally it was determined that an appropriate biofilm formulation has the following mass percentages: orange peel, 15; bacterial cellulose, 5; pectin, 40; and glycerol, 40. Such biofilm showed the following property values: tension stress at break, $5.53 \mathrm{~N} / \mathrm{mm}^{2}$; elongation at break, $51.60 \%$; and, water vapor permeability, 0.0273 g.mm/(h.kPa.m²).

Pectin content affected significantly the properties of the biofilms due to its interaction with glycerol. Bacterial cellulose contributed to increase the tension stress of the biofilm, but it reduced the value of elongation and water vapor permeability, which may be convenient for a diversity of applications. That is why bacterial cellulose constitutes an efficient reinforcing agent, whose production process is simple and safe.

Key words: biodegradable films, orange peel, bacterial cellulose, mechanical and barrier properties.

\section{INTRODUCCIÓN}

Las biopelículas aparecen como muy buena alternativa para mitigar la contaminación producida por el plástico, en vista de que se descomponen bajo condiciones ambientales. En tal sentido, la producción competitiva de biopelículas a partir de materias primas disponibles en el Perú, es una tarea que ofrece múltiples posibilidades. El presente estudio selecciona como componentes básicos de las biopelículas la cáscara de naranja, la celulosa bacteriana y el glicerol. La incorporación de la celulosa bacteriana a biopelículas es novedosa, pero muy promisoria porque se produce de modo seguro y a bajo costo. Por esto es de vital importancia evaluar el efecto de la adición de celulosa bacteriana sobre las propiedades de dichas biopelículas. En el presente estudio se produjo la celulosa bacteriana a partir de la fermentación del té negro, y se evaluó su aporte sobre las propiedades de las biopelículas ${ }^{1}$. Se podría potenciar la producción de té peruano (Camellia sinensis), para la producción de celulosa bacteriana y su posterior aplicación en biopelículas.

Es pertinente tomar como referencia el Análisis del Ciclo de Vida, en la elaboración de biopelículas, pues ofrece una valoración del impacto ambiental y de la economía de los productos. Dicho análisis evalúa el impacto ambiental de los materiales desde su producción, posterior manipulación, uso y disposición final, el que es regulado por la norma ISO 14040 y contribuye en la toma de decisiones sobre materias primas a emplear, modos de producción y especificaciones de los productos.

Entonces, desde la perspectiva del Análisis del Ciclo de Vida, la cáscara de naranja valenciana (citrus $x$ sinensis) empleada es un residuo industrial que se obtiene luego de la producción de jugo y aceite esencial (por arrastre de vapor), por ello su costo es sumamente bajo y se le estaría agregando valor y evitando que sea un elemento contaminante. De otro lado, la celulosa bacteriana, que es producida por la fermentación del té negro, es un recurso 
obtenido mediante un proceso biológico a bajo costo y con mínimo impacto ambiental. De esta fermentación el té negro es demandado como un agente nutracéutico, contribuyendo con una mayor valoración en el ciclo de vida.

Complementando este enfoque ecológico, se eligió como medio plastificante la glicerina, sustancia que aparece como subproducto de la esterificación en la producción de biodiesel y que se genera en grandes cantidades, constituyendo una amenaza potencial para el medio ambiente si no se encuentran usos rentables ${ }^{2}$.

Arévalo Niño y sus colaboradores ${ }^{3}$ trabajaron con cáscara de limón, pectina, glicerina, alcohol polivinílico y benzoato de sodio en la formación de películas monocapa y bicapa. Bátori y su grupo ${ }^{4}$, en cambio, reportaron la formación de biopelículas a partir de residuos industriales de naranja, pectina, glicerina, ácido cítrico y antiespumante; tales películas se caracterizan por su alta higroscopia.

La cáscara de naranja puede convertirse en un material esencial para la elaboración de biopelículas debido a su contenido en fibras de celulosa, pectina y aceites esenciales. La composición de la cáscara de naranja varía de acuerdo a la especie y a las condiciones de su cultivo. Dibanda y sus colaboradores ${ }^{5}$ reportaron que la naranja contiene 14,27 por ciento másico de cáscara; a su vez, la cáscara seca contiene 53,27 por ciento másico de carbohidratos. De otro lado, los residuos de naranja ${ }^{6}$ contienen los porcentajes másicos siguientes: pectina, 29,8; celulosa, 18,7; y, hemicelulosa, 20,9. Vale decir que el contenido de celulosa es cercano al veinte por ciento.

La pectina, está presente en frutas y hortalizas y, por tanto, es abundante en los desechos agrícolas. Se conforma por varias unidades de ácido poligalacturónico interrumpido por enlaces cortos de ramnosa. Es altamente soluble en agua y debido a su flexibilidad molecular otorga amplia deformación a las biopelículas, similar a la que se alcanza con algunos polímeros sintéticos ${ }^{6}$, por ejemplo las fibras de nylon y PET presentan valores de elongación entre 10 y 50 por ciento $^{7}$. Asimismo, bajo ciertas condiciones puede gelificar y constituir una barrera apropiada para la permeabilidad de gases ${ }^{8}$. Galus y su equipo de investigación ${ }^{9}$ indicaron que cuando la pectina se combina con otros polisacáridos se obtienen biopelículas continuas, homogéneas y transparentes que poseen un carácter hidrofílico.

El glicerol, también llamado glicerina o propanotriol $\left(\mathrm{C}_{3} \mathrm{H}_{8} \mathrm{O}_{3}\right)$, es un alcohol con tres grupos hidroxilos $(-\mathrm{OH})$, higroscópico, soluble en agua y ebulle a $290{ }^{\circ} \mathrm{C}$. Es el plastificante más popular para la producción de películas biodegradables debido a su alta disponibilidad, bajo costo, presenta compatibilidad con una amplia gama de materiales, ofrece buena elasticidad a las películas sin reducir significativamente la resistencia a la tensión, pero tiene dos inconvenientes: no reduce la permeabilidad al vapor de agua y es higroscópico, afectando el rango de aplicación de las biopelículas ${ }^{10}$. 
La celulosa bacteriana es similar a la celulosa de frutos como la naranja; sin embargo, es más pura ya que no contiene hemicelulosa, lignina o pectina; asimismo presenta mayor grado de polimerización (entre 4000 a 10000); así como más elevada cristalinidad (de 80 a $90 \%$ ) ${ }^{11}$, siendo también su capacidad de retención de agua y de rehidratación superiores ${ }^{12}$.

\section{PARTE EXPERIMENTAL}

La cáscara de naranja, a la cual se le extrajo su aceite esencial por arrastre de vapor, fue deshidratada, molida y clasificada, aceptando partículas con una granulometría inferior o igual a $140 \mu \mathrm{m}$.

La reproducción de la celulosa bacteriana se realiza en un sustrato consistente de una infusión que contiene $5 \mathrm{~g}$ de té negro y $70 \mathrm{~g}$ de azúcar por litro, la que se agita para disolver el azúcar y oxigenar la bebida. La cepa madre de kombucha (Manchurian fungus) se dispone con la parte brillante hacia arriba y su reproducción se realiza a $27{ }^{\circ} \mathrm{C}$ por un periodo de 7 a 15 días en un fermentador aireado. Posteriormente, se filtra el contenido del fermentador para retener la celulosa bacteriana y el líquido filtrado se emplea como bebida medicinal. La celulosa es sometida a un proceso de reducción de tamaño en húmedo, luego se deshidrata y se complementa la molienda en seco seleccionando las partículas de $+140 \mu \mathrm{m}$. La cepa madre de kombucha se ha adquirido del laboratorio del biólogo Tito Vicente Cuadros Pulcha, productor local registrado.

Las biopelículas se elaboraron mediante el método de vaciado en placas (casting). Las propiedades mecánicas se evaluaron de acuerdo a norma ASTM D882, correspondiente al método de prueba estándar para propiedades de tracción de láminas de plástico transparente con un espesor inferior a 1,0 mm. La permeabilidad al vapor de agua se determinó utilizando el método estándar propuesto por la norma ASTM E 96-95.

El trabajo experimental fue dividido en dos etapas. En la primera se buscó una formulación apropiada a partir de la cáscara de naranja, la pectina y el glicerol, para ello se evaluaron las siguientes formulaciones.

Tabla 1. Pruebas para definir la formulación adecuada.

\begin{tabular}{ccccl}
\hline $\begin{array}{l}\text { Nro. De } \\
\text { Experimento }\end{array}$ & $\begin{array}{c}\text { Cáscara de } \\
\text { naranja(\%)/p) }\end{array}$ & $\begin{array}{c}\text { Pectina } \\
(\mathbf{\%} / \mathbf{p})\end{array}$ & $\begin{array}{c}\text { Glicerina } \\
(\mathbf{\%} / \mathbf{p})\end{array}$ & Condiciones \\
\hline 1 & 30 & 30 & 40 & Temperatura $=$ \\
2 & 25 & 35 & 40 & $50-60{ }^{\circ} \mathrm{C}$ \\
3 & 20 & 40 & 40 & Velocidad $=$ \\
4 & 15 & 45 & 40 & $600 \mathrm{rpm}$ \\
5 & 10 & 50 & 40 & $\mathrm{pH}=6,0$ \\
\hline
\end{tabular}

Fuente. Elaboración propia 
En la segunda etapa se tomó como base la mejor biopelícula obtenida en la primera fase, que fue la que presentó mayor valor de resistencia a la tensión y porcentaje de elongación. En dicha mejor biopelícula se evaluó la sustitución parcial de cáscara de naranja por celulosa bacteriana.

Tabla 2. Experimentos para evaluar el efecto de la celulosa bacteriana.

\begin{tabular}{ccccc}
\hline $\begin{array}{c}\text { Nro. De } \\
\text { Experimento }\end{array}$ & $\begin{array}{c}\text { Cáscara de } \\
\text { naranja (gr) }\end{array}$ & $\begin{array}{c}\text { Pectina } \\
\text { (gr) }\end{array}$ & $\begin{array}{c}\text { Glicerina } \\
\text { (gr) }\end{array}$ & Celulosa B. (gr) \\
\hline 6 & 0 & 40 & 40 & 20 \\
7 & 15 & 40 & 40 & 05 \\
8 & 10 & 40 & 40 & 10 \\
9 & 5 & 40 & 40 & 15 \\
\hline
\end{tabular}

Fuente. Elaboración propia

\section{RESULTADOS Y DISCUSIÓN}

A continuación se evalúa el efecto de la composición de las biopelículas sobre sus propiedades, vale decir, resistencia a la tensión, elongación y permeabilidad al vapor de agua. Se organiza esta sección en dos etapas: la primera, estudia las películas base que no contienen celulosa bacteriana y; la segunda etapa, determina el efecto de la adición de celulosa bacteriana sobre las biopelículas.

\section{Primera Etapa.- Películas base}

A continuación se presentan los resultados correspondientes a las películas elaboradas a partir de cáscara de naranja, pectina y glicerina. Se reitera el hecho de que al aumentar la masa de pectina en la fórmula se reduce en la misma magnitud la cáscara de naranja. Por ejemplo, se tiene la fórmula con los porcentajes másicos siguientes: pectina $=30$; cáscara de naranja $=30 ; \mathrm{y}$, glicerol $=40$. Si se aumenta el contenido de pectina a $40 \%$; el de cáscara de naranja se reduce al $20 \%$.

En la figura 1 se observa que las propiedades mecánicas ostentan un comportamiento claramente no lineal. La resistencia a la tensión presenta un valor máximo de $5,92 \mathrm{~N} / \mathrm{mm}^{2}$, para un contenido de pectina del $35 \%$; en cambio la elongación de las películas es del $66 \%$ para una composición de $40 \%$ de pectina. La relación entre los valores experimentales máximo y mínimo es de 2,7 veces para la resistencia a la tensión, y de 2,1 veces para la elongación. La figura 1 también presenta la desviación estándar de cada corrida mediante barras verticales de error, apreciándose que los experimentos presentan una precisión significativa. 


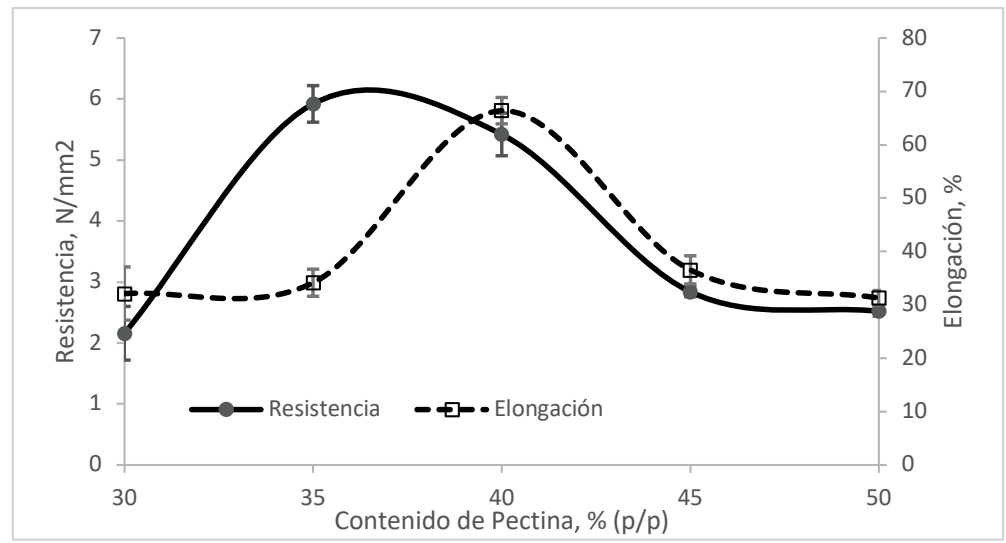

Figura 1. Variación de propiedades mecánicas por efecto de la pectina.

Los resultados anteriores coinciden con aquellos de Sánchez Aldana y colaboradores ${ }^{13}$, quienes evaluaron la formación de películas con extractos pécticos y aceite esencial de limón, empleando como plastificante el glicerol, reportaron que la resistencia a la tensión aumenta por efecto de la adición de glicerina y pectina; pero la permeabilidad al vapor de agua exhibe un comportamiento más complejo, pues aumenta con la concentración mayor de pectina, pero al incrementar la glicerina no siempre favorece el aumento de la permeabilidad.

La figura 2 presenta el perfil de la permeabilidad al vapor de agua de las películas cuando se modifica el contenido de pectina. Como se evidencia, los cambios son moderados, con una diferencia entre el valor máximo y el mínimo de sólo $16 \%$, registrándose un valor máximo de permeabilidad al vapor de agua de 0,029 g.mm/h.kPa.m2 para un contenido de pectina de $37 \%$, aproximadamente. Las barras de error de la figura 2 indican que la precisión de los resultados es aceptable.

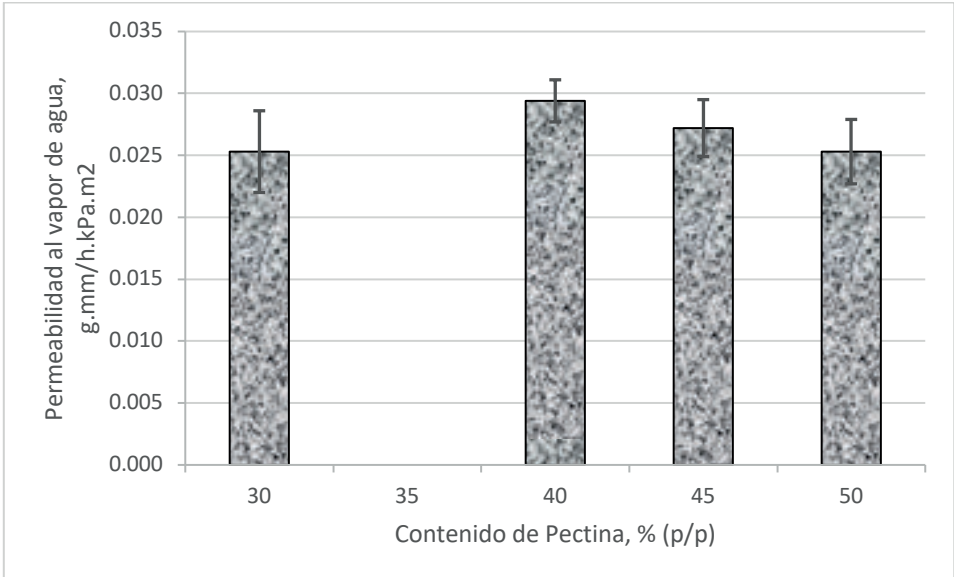

Figura 2. Efecto del contenido de pectina sobre la permeabilidad al vapor de agua. 
Para responder a la interrogante sobre cuál será el porcentaje de pectina conveniente en la fórmula para conformar la película, se ha seleccionado el valor de $40 \%$, basándose en las siguientes consideraciones: se obtuvo un máximo de elasticidad, y se está muy cerca del máximo de resistencia a la tensión; asimismo, se está próximo al máximo de permeabilidad al vapor de agua.

El comportamiento altamente no lineal de las propiedades de las películas por la adición de pectina encuentra sustento en los hallazgos de Fishman y sus colaboradores ${ }^{14}$, que evaluaron la interacción entre la pectina y el glicerol en biopelículas de almidón, encontrando que: (a) la presencia de glicerol en películas de pectina genera hasta tres transiciones termodinámicas, debido a la habilidad del glicerol de disociar redes de pectina ligadas por puentes de hidrógeno; y, (b) la microestructura de las cadenas laterales de la pectina cambia significativamente por la presencia del glicerol.

\section{Segunda Etapa.- Incorporación de celulosa bacteriana}

Esta segunda etapa toma como base la fórmula que contiene los siguientes porcentajes másicos excluyendo al agua que actúa como solvente: cáscara de naranja, 20; pectina, 40; y, glicerina, 40. Se evalúa la sustitución de cáscara de naranja por celulosa bacteriana, en los siguientes porcentajes másicos: $0,5,10,15$ y 20. La sumatoria del contenido de cáscara de naranja y celulosa bacteriana es constante e igual al $20 \%$ másico.

En la figura 3 se representan los resultados correspondientes a las propiedades mecánicas, vale decir, la resistencia a la tensión $\left(\mathrm{N} / \mathrm{mm}^{2}\right)$ en el punto de ruptura de la biopelícula y el porcentaje de elongación en este punto. Se aprecia que la sustitución de la cáscara de naranja por celulosa bacteriana permite incrementar la resistencia a la tensión de un modo lineal, logrando un aumento del $35 \%$; en cambio, la elongación se reduce casi hasta la mitad, desde $66 \%$ hasta $35 \%$.

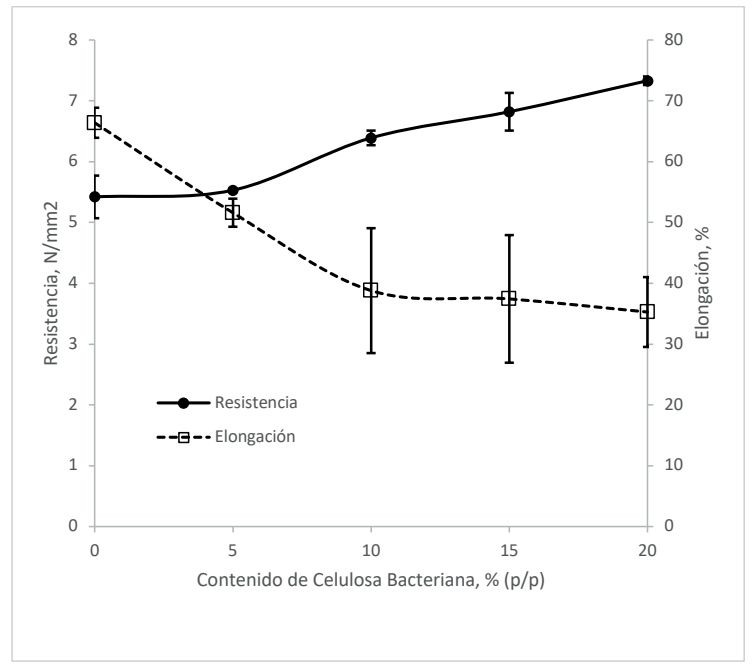

Figura 3. Cambios en las propiedades mecánicas por el contenido de celulosa bacteriana. 
La variación de la permeabilidad al vapor de agua por efecto de la adición de celulosa bacteriana se representa en la figura 4. Se aprecia que no se registran cambios significativos en la permeabilidad al vapor de agua por efecto de la adición de celulosa bacteriana, pero se observa un valor mayor en la permeabilidad al vapor de agua cuando el contenido de celulosa bacteriana es del $10 \%$.

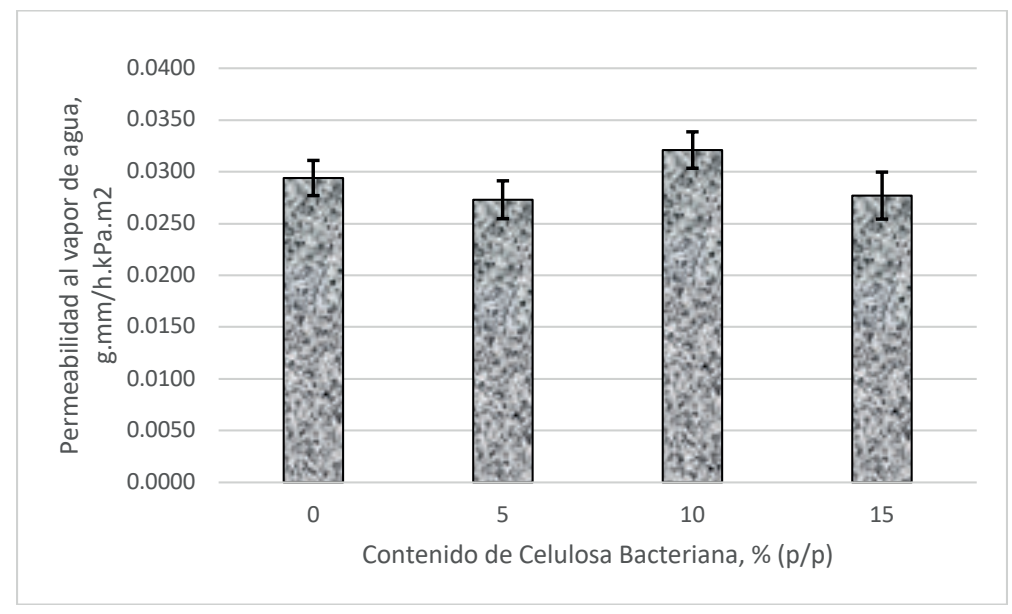

Figura 4. Modificación de la permeabilidad por el contenido de celulosa bacteriana.

Echeverry y sus colaboradores ${ }^{15}$ encontraron que el valor de la fuerza de tracción en el punto de rotura de películas de almidón de papa con glicerol, se incrementa en proporción lineal al contenido de microfibrillas de celulosa bacteriana. Nuestros resultados son coincidentes con estos hallazgos.

La adición de microfibras y nanofibras de celulosa en películas biodegradables fue estudiada por Andrade y su grupo ${ }^{16}$, destacando que constituyen un material de refuerzo que las propiedades mecánicas y de barrera. Una condición necesaria para una acción eficaz es la adecuada dispersión de estas partículas en la matriz polimérica de las películas. Señalan también que la concentración máxima de nanocristales de celulosa para alcanzar su adecuada dispersión es del $10 \%$ en masa en la matriz polimérica.

El rol de las fibras de celulosa, fue establecido por Müller y sus colaboradores ${ }^{17}$, en la formación de películas basadas en almidón, indicando que tales fibras actúan como un material de refuerzo que mejora la cristalinidad de las películas, permite alcanzar mayor resistencia a la tensión y reduce su elongación.

Arroyo Rosas ${ }^{18}$ explica que las fibrillas de celulosa ejercen un efecto de agente reforzante de la matriz polimérica debido a la formación de complejos de inclusión ,generando un 
incremento en la cristalinidad de la matriz, lo que reduce la movilidad de las cadenas amorfas, y el entrecruzamiento de dichas cadenas genera mayor rigidez. Una consecuencia obvia de esta mayor rigidez es la reducción de la elasticidad, el aumento de la fuerza para fracturar el material y el incremento de los valores de permeabilidad. Arroyo también indica que la formación de complejos se ve favorecida por la incorporación de surfactantes.

Complementariamente, Bátori y sus colaboradores ${ }^{4}$ señalan que la fuerza de las fibras de celulosa y la capacidad gelificante de la pectina se combinan para producir películas competitivas con los plásticos comerciales, a partir de residuos de naranja de la industria juguera.

Dado que las propiedades mecánicas presentan una relación lineal con respecto al contenido de celulosa bacteriana, se selecciona como fórmula final aquella que contiene los siguientes porcentajes expresados en términos de masa sobre masa total: celulosa bacteriana, 05; cáscara de naranja, 15; pectina, 40; y, glicerol, 40. Esta selección se basa en que la celulosa bacteriana en proporción de $5 \%(\mathrm{p} / \mathrm{p})$ genera una reducción en la permeabilidad al vapor de agua, lo cual es deseable para diversas aplicaciones, como la protección de alimentos. Así, también, dicha celulosa es más costosa que la cáscara de naranja.

\section{CONCLUSIONES}

Se logrón obtener biopelículas competitivas a partir de la cáscara de naranja a la cual se le ha extraído el aceite esencial, en combinación con pectina y glicerol. Al sustituir parcialmente la cáscara de naranja por celulosa bacteriana, obtenida a partir de la fermentación del té negro, se modificaron favorablemente las propiedades de las biopelículas. Se encuentra como conveniente un porcentaje de adición de celulosa bacteriana del $5 \%(\mathrm{p} / \mathrm{p})$, obteniendo una formulación final con los siguientes porcentajes másicos: cáscara de naranja, 15; celulosa bacteriana, 05; pectina, 40; y, glicerol, 40. Estas películas ostentaron una resistencia a la tensión de $5,53 \mathrm{~N} / \mathrm{mm}^{2}$, elongación de $51,60 \%$ y permeabilidad al vapor de agua de 0,0273 g.mm/(h.kPa.m²).

Los ensayos de las películas revelaron perfiles no lineales entre el contenido de pectina y la resistencia a la tensión, la elongación o la permeabilidad al vapor de agua; por el contrario, se presentaron relaciones lineales entre la concentración de celulosa bacteriana y el aumento de la resistencia a la tensión, la reducción de la elongación y la permeabilidad al vapor de agua. Por ello, la celulosa bacteriana se constituye en un agente reforzante efectivo cuya producción es sencilla y segura. 


\section{AGRADECIMIENTOS}

Se agradece a la Universidad Nacional de San Agustín por el financiamiento de tesis mediante contrato No 0018. Asimismo, los autores expresan su gratitud al Biólogo Tito Vicente Cuadros Pulcha, por su aporte en la adquisición de la cepa madre; y a Helbert Portugal Ochoa por su asistencia en la labor experimental.

\section{REFERENCIAS BIBLIOGRÁFICAS}

1. Carreño L, Calcedo L, Martínez C. Técnicas de Fermentación y aplicaciones de celulosa bacteriana: una revisión. Ingeniería y Ciencia. 2012; 8 (16):307-335.

2. Betancourt C, De Mello Prado R, Castellanos L, Campos SW. Características de la glicerina generada en la producción de biodiesel, aplicaciones generales y su uso en el suelo. CulTrop. 2016; 37(3): 7-14.

3. Arévalo K, Alemán M E, Rojas M G, Morales LA. Películas biodegradables a partir de residuos de cítricos: propuesta de empaques activos. Rev Latinoam Biotecnol Amb Algall. 2010; 1(2):124-134.

4. Bátori V, Jabbari M, Åkesson D, Lennartsson P, Taherzadeh M, Zamani A. Production of Pectin-Cellulose Biofilms: A New Approach for Citrus Waste Recycling. Int J Polym Sci. 2017. doi: 10.1155/2017/9732329.

5. Feumba DR, Ashwini RP, Ragu SM. Chemical composition of some selected fruit peels. Eur J Food Sci Technol. 2016; 4(4):12-21.

6. Coffin RD, Fishman ML. Viscoelastic properties of pectin-starch blends. J Agric Food Chem. 1993; 41 (8):1192-1197.

7. Coreña-Alonso A, Méndez Bautista M. Relación estructura-propiedades de polímeros. Edu Quim. 2010; 21(4):291-299.

8. Pérez Espitia P, Wen-Xian Du, Avena-Bustillos R, Ferreira Soares N, McHugh T. Edible films from pectin: Physical-mechanical and antimicrobial properties - A review. Food Hydrocoll. 2014; 35: 287-296.

9. Galus S, Lenart A. Development and characterization of composite edible films based on sodium alginate and pectin. J Food Eng. 2013; 115 (4): 459-465

10. Domínguez-Courtney MF, Jiménez Murguía MT. Películas comestibles formuladas con Polisacáridos: propiedades y aplicaciones. Temas Selectos de Ingeniería de Alimentos. 2012; 6 (2): 110-121.

11. Klemm D, Kramer F, Moritz S, Lindström T, Ankerfors M, Gray D, Dorris A. Nanocelluloses: A New Family of Nature-Based Materials. Angew Chem Int Ed Engl. 2011; 50(24): 5438-5466.

12. Chawla, Prashant R., Ishwar B. Bajaj, Shrikant A. Survase and Rekha S. Singhal. Microbial Cellulose: Fermentative Production and Applications. Food Technol Biotechnol. 2009; 47(2): 107-124.

13. Sánchez Aldana D, Contreras-Esquivel JC, Nevárez-Moorillón GV, Aguilar CN. Caracterización de películas comestibles a base de extractos pécticos y aceite esencial de limón mexicano. CyTA - J Food. 2015; 13(1):17-25. 
14. Fishman ML, Coffin DR, Unruh JJ, Ly T. Pectin/Starch/Glycerol Films: Blends or Composites? J Macromol Sci A. 1996; 33(5):639-654.

15. Echeverry N, Montoya U, Zuluaga R, Castro C, Gañan P. Películas de almidón de papa reforzadas con celulosa bacteriana. ReCiTelA. 2011. ISSN: 2027-6850.

16. Andrade MM, Tapia DR, Menegalli FC. Películas biodegradables: la incorporación de microfibras y nanofibras de celulosa obtenidas a partir de fuentes vegetales. Publicaciones e Investigación. 2011; 5: 11-28.

17. Müller C, Borges J, Yamashita F. Effect of cellulose fibers on the crystallinity and mechanical properties of starch based films at different relative humidity values. Carbohydr Polym. 2009; 77 (1): 293-299.

18. Arroyo K. Biocompósitos de almidón termoplástico con microfibras de celulosa. [Tesis para optar el grado de maestro en Tecnología Avanzada]. Altamira, México: Instituto Politécnico Nacional; 2008. 